\title{
Analisa $U X$ Writing terhadap User Experience pada Pengguna Aplikasi Grab
}

\author{
Karina Wongso, Wulan Purnama Sari \\ karina.915160048@stu.untar.ac.id,wulanp@fikom.untar.ac.id
}

Fakultas Ilmu Komunikasi Universitas Tarumanagara

\begin{abstract}
The high interest of Grab users can be seen from the success of a UX Writer in creating User Experience. User Experience assesses how satisfied someone is with products, systems and services. This research has a purpose to find out the effect of UX Writing that has been done by the UX Writer in Grab application to the User Experience. The theories that are used such as Brand, Branding, User Experience, and UX Writing. The method that is used is quantitative research with the survey method. The sampling technique that is used by the authors is the Non-probability Sampling with the Purposive Sampling. The total of samples is 100 respondents. Data collection method that is used is a questionnaire of Google forms that are distributed directly or online. The research phase was carried out by using a pre-test to 30 respondents, then doing a post-test to 100 respondents. The results of data processing indicate that there is an influence of the UX Writing $(X)$ on the User Experience $(Y)$. The most influential dimension on $U X$ Writing $(X)$ is visual, while the most influential dimension on User Experience $(Y)$ is branding.
\end{abstract}

Keywords: grab, user experience, ux writer, ux writing

\begin{abstract}
Abstrak
Tingginya minat pengguna Grab terlihat dari keberhasilan seorang UX Writer dalam menciptakan User Experience. User Experience menilai seberapa puas seseorang terhadap produk, sistem, dan jasa. Penelitian ini bertujuan untuk mengetahui pengaruh dari UX Writing yang dilakukan oleh $U X$ Writer aplikasi Grab terhadap User Experience kepada pengguna aplikasi Grab. Teori yang digunakan dalam penelitian ini adalah Brand, Branding, User Experience, dan $U X$ Writing. Metode penelitian yang digunakan adalah pendekatan penelitian kuantitatif dengan metode survei. Teknik pengambilan sampel yang digunakan penulis dalam penelitian ini adalah teknik Non-probability Sampling dengan pendekatan Purposive Sampling. Pada penelitian ini, penulis menetapkan jumlah sampel sebanyak 100 responden. Tahap penelitian yang dilakukan adalah dengan menggunakan pre-test kepada 30 responden, kemudian melakukan post-test kepada 100 responden. Hasil pengolahan data menunjukkan bahwa terdapat pengaruh dari variabel $U X$ Writing $(\mathrm{X})$ terhadap variabel User Experience (Y) pada pengguna aplikasi Grab. Dimensi yang paling berpengaruh pada variabel UX Writing (X) adalah visual, sedangkan dimensi yang paling berpengaruh pada variabel User Experience (Y) adalah branding.
\end{abstract}

Kata Kunci: grab, user experience, ux writer, ux writing

\section{Pendahuluan}

Fenomena ojek online mengubah sesuatu yang tadinya bersifat konvensional menjadi modern. Awalnya, seorang penumpang menghampiri ojek untuk melakukan perjalanan sesuai yang diinginkan, sedangkan sekarang menjadi ojek yang menghampiri penumpang sesuai titik alamat penjemputan. Sebelumnya jika ingin 
berpergian menggunakan ojek hanya bisa membayar biaya perjalanannya dengan uang tunai, tetapi sekarang tanpa membayar dengan menggunakan uang tunai juga sudah bisa. Hal ini dikarenakan oleh semakin canggihnya teknologi membuat sistem pembayaran yang tadinya masih tradisional menjadi modern yaitu dengan sistem pembayaran digital.

Cara pemesanan ojek online-pun sangat mudah sehingga terlihat sangat jelas pastinya manusia menjadi mulai beralih menggunakan ojek online. Hal ini tentunya menimbulkan pro dan kontra. Ojek konvensional seperti ojek-ojek pangkalan menjadi merasa dirugikan dengan kehadiran ojek online karena calon penumpangnya jadi berkurang dan menjadi merasa tidak adil. Tetapi semua itu tidak membuat ojek online menjadi hilang atau ditutup. Sampai sekarang ojek online tetap bertahan bahkan saling bersaing karena semua orang sudah mulai menggunakan ojek online. Hal ini juga tidak membuat ojek-ojek pangkalan menjadi tidak ada lagi, karena tidak semua orang mempunyai aplikasi ojek online (HMT ITB, 2017).

Transportasi online bermula dari ojek online yang saat ini sudah hampir ada di seluruh wilayah Indonesia, yaitu 2 perusahaan besar seperti Gojek dan Grab. Persaingan antara Gojek dan Grab sangat ketat. Gojek berasal dari Indonesia dan didirikan oleh pengusaha Indonesia bernama Nadiem Anwar Makarim sedangkan Grab didirikan oleh pengusaha yang berasal dari Malaysia bernama Anthony Tan. Meskipun Grab berasal dari Malaysia, tetapi Grab tetap bisa jadi perusahaan besar di Indonesia dan tidak kalah bersaing dengan Gojek. Hal ini terlihat dari tingginya minat pengguna jasa Grab di Indonesia (Fino Yurio Kristo, 2018).

$U X$ adalah singkatan dari User Experience. Menurut definisi dari ISO 9241210, User Experience adalah persepsi seseorang dan responnya dari penggunaan sebuah produk, sistem, atau jasa (Wiryawan, 2011). UX Writer adalah seseorang yang mempunyai harapan untuk mempermudah dalam memakai suatu produk, salah satu contohnya adalah aplikasi. Caranya dengan merangkai kata-kata yang secukupnya dan tidak membuat pengguna produk merasa bosan. Tugas dari UX Writer adalah membuat User Experience (Edwin Mohammad, 2018).

Tingginya minat pengguna menggunakan jasa Grab juga berkaitan dengan keberhasilan seorang $U X$ Writer dalam membuat kata-kata yang dapat menarik perhatian pengguna jasa Grab untuk selalu tetap menggunakan aplikasi Grab. Salah satunya adalah dalam bentuk notifikasi-notifikasi yang biasanya dikirimkan oleh aplikasi Grab kepada pengguna jasa Grab. Seorang UX Writer tentunya harus terus memikirkan kata-kata yang unik dan tidak membosankan agar pengguna jasa Grab tidak beralih ke aplikasi transportasi online lainnya.

Penulis berusaha untuk mengetahui apakah terdapat pengaruh dari UX Writing yang dilakukan oleh $U X$ Writer aplikasi Grab terhadap User Experience kepada pengguna jasa Grab. Maka, penulis mengajukan penelitian berjudul "Analisa $\boldsymbol{U} \boldsymbol{X}$ Writing Terhadap User Experience Pada Pengguna Aplikasi Grab”.

Fokus permasalahan yang akan dijadikan sebagai topik utama adalah apakah $U X$ Writing dan User Experience berpengaruh terhadap kepuasan pengguna jasa Grab dan apakah persepsi pengguna terhadap $U X$ Writer yang dimiliki oleh Grab. Tujuan dari penelitian yang dilakukan adalah untuk mengetahui apakah $U X$ Writing dan User Experience berpengaruh terhadap kepuasan pengguna jasa Grab dan untuk mengetahui persepsi pengguna terhadap UX Writer yang dimiliki oleh Grab. Konsep teori yang digunakan oleh penulis adalah Brand, Branding, User Experience, dan UX Writing. Penulis mengambil contoh penelitian terdahulu untuk mendukung dan memperkuat hasil uji dari penelitian ini, salah satunya adalah penelitian terdahulu yang dilakukan oleh 
Gregorius Genep Sukendro dan Nigar Pandrianto, dosen dari Fakultas Ilmu Komunikasi Universitas Tarumanagara yang berjudul Diagnosa Komunikasi Brand Activation Dan Media Digital Atas Eksistensi Brand Studio Rekaman Lokananta, dari penelitian terdahulu itu penulis mendapatkan banyak referensi dengan adanya persamaan pada teori penelitian yang digunakan yaitu Brand. Selain itu, penulis juga mengambil penelitian terdahulu yang dilakukan oleh Cut Putri Chandra dan Sinta Paramita dari Fakultas Ilmu Komunikasi Universitas Tarumanagara yang berjudul Corporate Branding Bioskop Dalam Industri Hiburan (Studi Kasus Cinema 21 Group Dengan CGV Cinemas), dari penelitian terdahulu tersebut, penulis juga mendapatkan banyak referensi seperti adanya persamaan pada teori penelitian yang digunakan yaitu Brand dan Branding.

Gambar 1. Kerangka Pemikiran

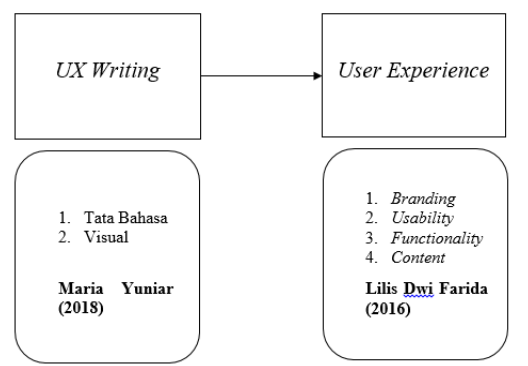

Sumber: Dokumentasi Peneliti (2019)

\section{Metode Penelitian}

Pada penelitian ini, penulis menggunakan pendekatan penelitian kuantitatif dengan metode survei sebagai metode penelitian yang akan digunakan. Sugiyono (2011) menyatakan bahwa penelitian kuantitatif melihat hubungan variabel terhadap obyek yang diteliti yang mempunyai sifat sebab dan akibat (kausal). Oleh karena itu, dalam penelitiannya terdapat variabel independen dan dependen. Dari variabel tersebut, dapat dicari pengaruhnya seberapa besar yang terjadi dari variabel independen terhadap variabel dependen.

Berdasarkan pembahasan mengenai penelitian kuantitatif yang telah diuraikan, penulis memilih pendekatan penelitian kuantitatif karena merasa paling sesuai dengan topik penelitian penulis. Dengan menggunakan pendekatan penelitian kuantitatif, penulis dapat melihat seberapa besar pengaruh dari UX Writing terhadap User Experience pada pengguna aplikasi Grab.

Teknik pengambilan sampel yang digunakan penulis dalam penelitian ini adalah teknik Non-probability Sampling. Teknik Non-probability Sampling yang digunakan adalah Purposive Sampling. Dalam penelitian ini, data primer yang didapatkan adalah dengan menggunakan kuesioner (angket) yang disebarkan kepada responden dengan kriteria sebagai pengguna aplikasi Grab, berusia 17-25 tahun serta berdomisili di Jakarta. Tahapan penelitian yang dilakukan adalah dengan menggunakan pre-test sebanyak 30 responden, kemudian melakukan post-test sebanyak 100 responden. Kuesioner yang digunakan oleh penulis untuk mengumpulkan data diukur dengan menggunakan skala likert. 
Pengolahan data yang dilakukan oleh penulis adalah dengan menggunakan software SPSS (Statistical Product and Service Solution) untuk Windows versi 15. Teknik pengolahan dan analisis data yang digunakan pada penelitian ini adalah koefisien determinasi $\left(\mathrm{R}^{2}\right)$, analisis regresi linier sederhana, uji T (uji parsial), dan uji F. Sedangkan teknik keabsahan data yang digunakan pada penelitian ini adalah uji validitas, uji reliabilitas, dan uji normalitas.

\section{Hasil Temuan dan Diskusi}

Responden yang diteliti dalam penelitian ini adalah pengguna aplikasi Grab yang berusia 17-25 tahun dan berdomisili di Jakarta. Kuesioner ini disebarkan oleh peneliti melalui google form yang disebarkan secara langsung maupun online. Kuesioner disebarkan mulai tanggal 15 Oktober 2019 sampai dengan 28 Oktober 2019. Tahap penelitian ini dengan menggunakan pre-test kepada 30 responden, kemudian melakukan post-test kepada 100 responden. Berdasarkan data karakteristik responden, dari 100 responden terdapat 37 responden (37\%) berjenis kelamin laki-laki dan 63 responden (63\%) berjenis kelamin perempuan dengan mayoritas responden berusia 21 sampai dengan 22 tahun, dan berdomisili di Jakarta Barat. Berikut adalah hasil keabsahan data yang digunakan pada penelitian ini:

\section{Uji Validitas}

\begin{tabular}{ccc} 
Tabel 1. Hasil Uji Validitas $U X$ Writing $(\mathrm{X})$ \\
\hline Butir Pernyataan & $\begin{array}{c}\text { Corrected } \\
\text { Item-Total } \\
\text { Correlation }\end{array}$ & Keterangan \\
\hline UX1 & 0.687 & Valid \\
UX2 & 0.647 & Valid \\
UX3 & 0.554 & Valid \\
UX4 & 0.683 & Valid \\
UX5 & 0.616 & Valid \\
UX6 & 0.645 & Valid \\
UX7 & 0.633 & Valid \\
UX8 & 0.684 & Valid \\
UX9 & 0.543 & Valid \\
UX10 & 0.502 & Valid \\
\hline
\end{tabular}

Sumber: Pengolahan Data SPSS 15 (2019)

Tabel 2. Hasil Uji Validitas User Experience (Y)

\begin{tabular}{ccc}
\hline $\begin{array}{c}\text { Butir } \\
\text { Pernyataan }\end{array}$ & $\begin{array}{c}\text { Corrected } \\
\text { Item-Total } \\
\text { Correlation }\end{array}$ & Keterangan \\
\hline UE1 & 0.544 & Valid \\
UE2 & 0.513 & Valid \\
UE3 & 0.352 & Valid \\
UE4 & 0.486 & Valid \\
UE5 & 0.617 & Valid \\
UE6 & 0.287 & Valid \\
UE7 & 0.556 & Valid \\
UE8 & 0.642 & Valid
\end{tabular}


Karina Wongso, Wulan Purnama Sari: Analisa UX Writing terhadap User Experience pada Pengguna Aplikasi Grab

\begin{tabular}{ccc} 
UE9 & 0.567 & Valid \\
UE10 & 0.568 & Valid \\
UE11 & 0.688 & Valid \\
UE12 & 0.491 & Valid \\
UE13 & 0.515 & Valid \\
UE14 & 0.609 & Valid \\
UE15 & 0.642 & Valid \\
UE16 & 0.664 & Valid \\
\hline \multicolumn{2}{l}{ Sumber: Pengolahan Data SPSS 15 (2019) }
\end{tabular}

Berdasarkan hasil uji validitas dari variabel $U X$ Writing $(\mathrm{X})$ dan variabel User Experience (Y) di atas, dapat dinyatakan bahwa setiap pernyataan seluruhnya valid karena nilai dari Corrected Item Total Correlation lebih besar dari 0,200.

\section{Uji Reliabilitas}

Tabel 3. Hasil Uji Reliabilitas

\begin{tabular}{ccc}
\hline Variabel & Nilai Cronbach's Alpha & Keterangan \\
\hline UX Writing $(\mathrm{X})$ & 0.886 & Reliable \\
User Experience $(\mathrm{Y})$ & 0.886 & Reliable \\
\hline
\end{tabular}

Sumber: Pengolahan Data SPSS 15 (2019)

Berdasarkan hasil uji reliabilitas dari variabel $U X$ Writing $(\mathrm{X})$ dan variabel User Experience (Y) di atas, dapat dinyatakan bahwa seluruh variabel yang digunakan dalam penelitian ini reliabel karena nilai Cronbach's Alpha masingmasing variabel lebih besar dari 0,6.

\section{Uji Normalitas}

Tabel 4. Hasil Uji Normalitas

\begin{tabular}{|c|c|c|}
\hline & & $\begin{array}{l}\text { Unstandardiz } \\
\text { ed Residual }\end{array}$ \\
\hline \multicolumn{2}{|l|}{$N$} & 100 \\
\hline Normal & Mean & .0000000 \\
\hline Parameters $(a, b)$ & Std. Deviation & .50760163 \\
\hline Most Extreme & Absolute & .114 \\
\hline \multirow[t]{2}{*}{ Differences } & Positive & .114 \\
\hline & Negative & -.082 \\
\hline \multicolumn{2}{|c|}{ Kolmogorov-Smirnov $Z$} & 1.140 \\
\hline \multicolumn{2}{|c|}{ Asymp. Sig. (2-tailed) } & .149 \\
\hline
\end{tabular}

Sumber: Pengolahan Data SPSS 15 (2019)

Berdasarkan hasil uji normalitas dari variabel $U X$ Writing $(\mathrm{X})$ dan variabel User Experience (Y) di atas, dapat dinyatakan bahwa nilai Asymp. Sig. (2-tailed) adalah 0,149>0,05. Dengan demikian, dapat disimpulkan bahwa distribusi dari seluruh variabel dalam kondisi normal. 


\section{Rata-rata (Mean)}

Tabel 5. Rata-rata (Mean) Variabel $U X$ Writing (X)

\begin{tabular}{ccc}
\hline Dimensi & N & Mean \\
\hline Tata Bahasa & 6 & 3.7 \\
Visual & 4 & 3.72 \\
\hline
\end{tabular}

Sumber: Pengolahan Data SPSS 15 (2019)

Berdasarkan hasil rata-rata (Mean) dari variabel $U X$ Writing (X) di atas, dapat dinyatakan bahwa dimensi visual paling berpengaruh pada variabel UX Writing (X).

Tabel 6. Rata-rata (Mean) Variabel User Experience (Y)

\begin{tabular}{ccc}
\hline Dimensi & N & Mean \\
\hline Branding & 4 & 3.65 \\
Usability & 4 & 3.49 \\
Functionality & 2 & 3.53 \\
Content & 6 & 3.56 \\
\hline
\end{tabular}

Sumber: Pengolahan Data SPSS 15 (2019)

Berdasarkan hasil rata-rata (Mean) dari variabel User Experience (Y) di atas, dapat dinyatakan bahwa dimensi Branding paling berpengaruh pada variabel User Experience $(\mathrm{Y})$. Berikut adalah hasil pengolahan dan analisis data yang digunakan pada penelitian ini.

\section{Koefisien Determinasi $\left(\mathbf{R}^{2}\right)$}

Tabel 7. Hasil Koefisien Determinasi $\left(\mathrm{R}^{2}\right)$

\begin{tabular}{lrrrr}
\hline & & \multicolumn{2}{c}{ Adjusted } & Std. Error of \\
Model & $R$ & $R$ Square & $R$ Square & the Estimate \\
\hline 1 & $.371^{\mathrm{a}}$ & .137 & .129 & .51018 \\
\hline
\end{tabular}

Sumber: Pengolahan Data SPSS 15 (2019)

Berdasarkan hasil koefisien determinasi $\left(\mathrm{R}^{2}\right)$ dari variabel $U X$ Writing $(\mathrm{X})$ dan variabel User Experience (Y) di atas, dapat dinyatakan bahwa hasil yang diperoleh dengan menggunakan nilai $R$ Square adalah sebesar 0,137 . Hal ini berarti bahwa pengaruh variabel $U X$ Writing (X) terhadap variabel User Experience (Y) adalah sebesar $13,7 \%$ dan sisanya dengan persentase $86,3 \%$ dipengaruhi oleh faktor-faktor lain yang tidak dijelaskan di dalam penelitian ini.

\section{Analisis Regresi Linier Sederhana}

Tabel 8. Hasil Analisis Regresi Linier Sederhana

\begin{tabular}{|c|c|c|c|c|c|c|}
\hline \multirow[b]{2}{*}{ Model } & & \multicolumn{2}{|c|}{$\begin{array}{c}\text { Unstandardized } \\
\text { Coefficients }\end{array}$} & \multirow{2}{*}{$\begin{array}{c}\text { Standardized } \\
\text { Coefficients } \\
\text { Beta }\end{array}$} & \multirow[b]{2}{*}{$t$} & \multirow[b]{2}{*}{ Sig. } \\
\hline & & $B$ & Std. Error & & & \\
\hline 1 & (Constant) & 2.371 & .305 & & 7.768 & .000 \\
\hline & UX Writing & .321 & .081 & .371 & 3.950 & .000 \\
\hline
\end{tabular}

Sumber: Pengolahan Data SPSS 15 (2019) 
Karina Wongso, Wulan Purnama Sari: Analisa UX Writing terhadap User Experience pada Pengguna Aplikasi Grab

Berdasarkan tabel 8 di atas, dapat dinyatakan bahwa nilai konsisten dari variabel User Experience adalah sebesar 2,371 dan koefisien regresi X adalah sebesar 0,321 menyatakan bahwa setiap penambahan $1 \%$ nilai $U X$ Writing, maka nilai User Experience bertambah sebesar 0,321. Koefisien regresi tersebut bernilai positif, sehingga dapat dikatakan bahwa arah pengaruh variabel $\mathrm{X}$ terhadap $\mathrm{Y}$ adalah positif.

\section{Uji T (Uji Parsial)}

Berdasarkan tabel 8, pengambilan keputusan dalam uji regresi sederhana adalah dari tabel Coefficients diperoleh nilai signifikansi sebesar 0,000 $<0,05$, sehingga dapat dinyatakan bahwa variabel $U X$ Writing (X) berpengaruh terhadap variabel User Experience (Y) dan berdasarkan nilai t (Uji T), dapat diketahui bahwa nilai $t_{\text {hitung }}$ sebesar 3,950 $>\mathrm{t}_{\text {tabel }}$ 1,984. Hal ini menunjukkan bahwa $\mathrm{H}_{\mathrm{o}}$ ditolak dan $\mathrm{H}_{\mathrm{a}}$ diterima sehingga dapat disimpulkan bahwa variabel $U X$ Writing $(\mathrm{X})$ berpengaruh terhadap variabel User Experience (Y).

\section{Uji F}

\begin{tabular}{llrrrrr}
\hline Model & & Sum of & & & \\
Squares & df & Mean Square & \multicolumn{1}{c}{ S } & \multicolumn{1}{c}{ Sig. } \\
\hline 1 & Regression & 4.061 & 1 & 4.061 & 15.603 & $.000^{\mathrm{a}}$ \\
& Residual & 25.508 & 98 & .260 & & \\
& Total & 29.570 & 99 & & & \\
\cline { 2 - 6 }
\end{tabular}

Sumber: Pengolahan Data SPSS 15 (2019)

Berdasarkan tabel 9 di atas, dapat dinyatakan bahwa hasil uji hipotesis

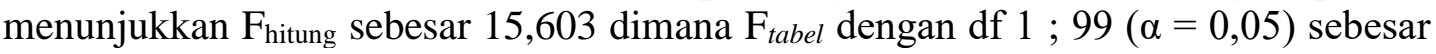
3,94. Hasil tersebut menunjukkan $F_{\text {hitung }} 15,603>F_{\text {tabel }}$ 3,94 maka $\mathrm{H}_{\mathrm{o}}$ ditolak dan $\mathrm{H}_{\mathrm{a}}$ diterima. Oleh karena itu, dapat disimpulkan bahwa variabel $U X$ Writing (X) dinyatakan berpengaruh secara simultan terhadap variabel User Experience (Y).

\section{Pembahasan}

Garrett (2011) menyatakan bahwa User Experience bukanlah mempelajari tentang proses kerja dari suatu produk atau layanan yang ada, melainkan interaksi seperti apa yang dilakukan antara user dengan suatu produk. Contohnya adalah pengalaman pengguna dalam menggunakan suatu produk. Pengalaman pengguna tersebut meliputi apakah produk mudah untuk digunakan, sesederhana apa dalam mengoperasikan suatu produk hingga menciptakan pengalaman yang dapat menemukan dan memahami informasi-informasi yang telah tersedia. Sesuai dengan hasil penelitian, dimensi yang paling berpengaruh pada variabel User Experience adalah branding. Hal ini berarti bahwa branding dari Grab memiliki nilai penting dalam User Experience. Sedangkan dimensi yang paling berpengaruh pada variabel $U X$ Writing adalah visual, dimana artinya tampilan dari notifikasi berpengaruh dalam penilaian User Experience.

Wheeler (2009) mendefinisikan branding sebagai proses yang dilakukan untuk membangun kesadaran konsumen dan meningkatkan kesetiaan konsumen terhadap suatu produk. UX Writing pada aplikasi Grab dapat dikatakan berhasil dalam memasarkan jasa-jasa yang telah disediakan oleh Grab terutama dari setiap tata bahasa dan visual untuk setiap notifikasi yang dikirimkan kepada penggunanya dan 
kemudahan pengguna dalam menggunakan fitur-fitur yang ada. Terlihat dengan jelas bahwa dalam pemasaran dan penciptaan branding, $U X$ Writing juga memiliki peran yang sangat penting. Keberhasilan $U X$ Writing pada aplikasi Grab menyebabkan responden (pengguna Grab) tetap setia untuk menggunakan Grab.

Maria Yuniar (2018) mengatakan bahwa kunci keberhasilan dari UX Writing adalah bagaimana $U X$ Writer mengolah kata-kata yang kreatif dengan tata bahasa yang benar dan tepat sehingga dapat membuat orang-orang jadi merasa tertarik dengan suatu produk atau jasa. Selain itu, bagaimana seorang UX Writer membuat tulisan User Experience yang ada hubungannya antara konten yang diciptakan dengan penggunanya. Hal ini disebabkan karena pengguna lebih suka mencari dan membaca konten yang berkaitan dengan persoalan mereka terhadap suatu produk atau layanan.

Berdasarkan pengolahan data, hasil penelitian ini menunjukkan bahwa responden (pengguna Grab) merasa puas dengan jasa-jasa yang disediakan oleh Grab karena konten-konten yang dibuat sangat berhubungan dengan kebutuhan penggunanya seperti misalnya pengguna dapat membeli makan dengan harga yang terjangkau oleh karena adanya potongan harga atau promo makanan yang diberikan oleh Grab. Selain itu, pengguna juga dapat menikmati perjalanan ke tempat yang ingin dituju dengan harga yang murah oleh karena memakai potongan harga atau promo layanan GrabBike, GrabCar dan lainnya yang dikirimkan oleh aplikasi Grab melalui inbox dalam bentuk notifikasi. Terbukti dengan jelas bahwa $U X$ Writing yang dimiliki oleh Grab sudah menciptakan konten-konten yang sesuai dengan kebutuhan penggunanya dan hal tersebut sangat berpengaruh pada User Experience terhadap Grab.

\section{Simpulan}

Berdasarkan hasil pengolahan data, dapat disimpulkan bahwa dalam penelitian ini terdapat pengaruh pada variabel $U X$ Writing $(\mathrm{X})$ terhadap variabel User Experience (Y). Dimensi yang paling berpengaruh pada variabel $U X$ Writing (X) adalah visual, sedangkan dimensi yang paling berpengaruh pada variabel User Experience (Y) adalah branding. Hal ini berarti bahwa $U X$ Writing pada aplikasi Grab dinyatakan berhasil dalam menciptakan User Experience yang positif terhadap Grab. UX Writing pada aplikasi Grab sangat mempengaruhi kepuasan pengguna Grab sehingga menyebabkan responden (pengguna Grab) jadi tetap setia untuk menggunakan jasa Grab secara berulang-ulang kali. Selain itu, setiap notifikasi yang dikirimkan oleh aplikasi Grab juga tidak jarang memberikan perhatian kepada penggunanya sehingga pengguna memberikan feedback yang baik terhadap Grab karena merasa diperhatikan oleh Grab. Responden (pengguna Grab) merasa puas dengan jasa-jasa yang disediakan oleh Grab karena $U X$ Writing yang dimiliki oleh Grab sudah menciptakan konten-konten yang berhubungan dengan kebutuhan penggunanya. Oleh karena itu, dapat disimpulkan bahwa $U X$ Writing yang dibuat oleh $U X$ Writer Grab pada aplikasi Grab berhasil dalam menciptakan User Experience yang positif terhadap Grab.

\section{Ucapan Terima Kasih}

Penulis mengucapkan terima kasih kepada orang tua dan teman-teman yang telah memberikan doa, semangat, dan dukungan kepada penulis selama proses penelitian ini serta seluruh responden yang telah memberikan kesediaan untuk bekerja sama selama proses penelitian ini. 
Karina Wongso, Wulan Purnama Sari: Analisa UX Writing terhadap User Experience pada Pengguna Aplikasi Grab

\section{Daftar Pustaka}

Chandra, Cut Putri., \& Paramita, Sinta. (2018). Corporate Branding Bioskop Dalam Industri Hiburan (Studi Kasus Cinema 21 Group Dengan CGV Cinemas). Jurnal Prologia, 2 (1).

Garrett, Jesse James. (2011). The Elements of User Experience: User-Centered Design for the Web and Beyond. Second Edition. California: New Riders.

Himpunan Mahasiswa Tambang Institut Teknologi Bandung. (2017, Maret 24). ProKontra Transportasi Online. September 7, 2019. https://hmt.mining.itb.ac.id/pro-kontra-transportasi-online/

Kristo, Fino Yurio. (2018, Maret 29). Kisah Lulusan Harvard Jadikan Gojek \& Grab Bisnis Triliunan. September 8, 2019. Detikinet Database. https://inet.detik.com/business/d-3942831/kisah-lulusan-harvard-jadikanGojek--grab-bisnis-triliunan

Mohammad, Edwin. (2018, November 22). Ngobrol Tentang UX Writer Bareng Edwin Mohammad, Lead UX Writer di Gojek. Agustus 24, 2019. Medium Database. https://medium.com/insightdesign/ngobrol-tentang-ux-writerbareng-edwin-mohammad-lead-ux-writer-di-Gojek-c8f85dc78809

Sugiyono. (2011). Metode Penelitian Pendidikan. Bandung: Alfabeta.

Sukendro, Gregorius Genep., \& Pandrianto, Nigar. (2019). Diagnosa Komunikasi Brand Activation dan Media Digital Atas Eksistensi Brand Studio Rekaman Lokananta. Jurnal Komunikasi, 11 (1), 92-107.

Wheeler, Alina. (2009). Designing Brand Identity. Edisi 3. Wiley: Canada.

Wiryawan, Mendiola B. (2011). User Experience (UX) sebagai Bagian dari Pemikiran Desain dalam Pendidikan Tinggi Desain Komunikasi Visual. Jurnal Humaniora, 2 (2), 1158-1166.

Yuniar, Maria. (2019, Oktober 10). Apa saja yang dikerjakan UX Writer. September 17, 2019. Ekrut Media Database. https://www.ekrut.com/media/apa-saja-yangdikerjakan-ux-writer 